\title{
Stress reduces the incorporation of misinformation into an established memory
}

\author{
Pia-Isabell Schmidt, ${ }^{1}$ Kristin Rosga, ${ }^{1}$ Celina Schatto, ${ }^{1}$ Anja Breidenstein, ${ }^{2}$ \\ and Lars Schwabe ${ }^{1,2,3}$ \\ ${ }^{1}$ Institute of Experimental Psychology, Department of Biological Psychology, Heinrich-Heine University Düsseldorf, 40225 \\ Düsseldorf, Germany; ${ }^{2}$ Institute of Cognitive Neuroscience, Department of Cognitive Psychology, Ruhr-University Bochum, \\ 44780 Bochum, Germany
}

\begin{abstract}
Memory can be distorted by misleading post-event information. These memory distortions may have serious consequences, for example in eyewitness testimony. Many situations in which memory reports are solicited, and suggestive or misleading information is presented, are highly stressful for the respondent, yet little is known about how stress affects people's susceptibility to misinformation. Here, we exposed participants to a stressor or a control manipulation before they were presented misinformation about a previous event. We report that stressed participants endorsed misinformation in a subsequent memory test less often than control participants, suggesting that stress reduces distortions of memory by misleading information.
\end{abstract}

[Supplemental material is available for this article.]

Human memory does not work like a videotape. It rather is a highly dynamic, constructive process that is susceptible to distortions and errors (Schacter 1999). Perhaps one of the most prominent examples for the malleability of memory comes from studies on the "misinformation effect" showing that memory can be distorted by misleading post-event information (Loftus et al. 1978; for review, see Loftus 2005). When people are asked suggestive and misleading questions about a previous event, many will inadvertently incorporate elements from the misinformation into their memory of the original event. Functional neuroimaging suggests that the hippocampus plays a critical role in the misinformation effect. In particular, hippocampal activity during the presentation of misleading information about a previous event predicted whether the misinformation would be incorporated into memory (Okado and Stark 2005).

The hippocampus is one of the brain areas that is most sensitive to stress (de Kloet et al. 2005). Stress and glucocorticoid stress hormones (cortisol in humans) suppress memory-related neuroplasticity processes in the hippocampus (Kim and Diamond 2002; Diamond et al. 2007) and reduce hippocampal activity during learning (Schwabe and Wolf 2012). Although stress may have both enhancing and impairing effects on hippocampusdependent memory, depending on the timing of the stressor (Diamond et al. 2007; Joëls et al. 2011; Schwabe et al. 2012a), there is compelling evidence that stress before encoding may disrupt hippocampal memory (Diamond et al. 1999, 2006; Payne et al. 2007; Schwabe et al. 2009; but see Karst et al. 2005, Diamond et al. 2007, and Li and Richter-Levin 2013 for rapid enhancements of hippocampal memory or neuroplasticity by predator stress, glucocorticoids, or amygdala stimulation). Given the role of the hippocampus in the misinformation effect, these data suggest that stress before misinformation presentation may hamper the incorporation of misleading information into memory.

\section{${ }^{3}$ Corresponding author}

E-mail Lars.Schwabe@rub.de

Article is online at http://www.learnmem.org/cgi/doi/10.1101/Im.033043.113.
Further support for this hypothesis comes from work on memory reconsolidation. Accumulating evidence indicates that memory retrieval renders seemingly stable memories labile, requiring another period of stabilization, termed reconsolidation, during which memories can be modified (for review, see Hardt et al. 2010). It has recently been hypothesized that reconsolidation is the mechanism that mediates the misinformation effect (Hupbach et al. 2007; Schacter et al. 2011). Interestingly, the reconsolidation of episodic memories involves also the hippocampus (Schwabe et al. 2012b), and human and rodent studies suggest that stress and glucocorticoids impair reconsolidation processes (Maroun and Akirav 2008; Schwabe and Wolf 2010).

Distortions of memory by misinformation have important implications for eyewitness testimony (Schacter and Loftus 2013), for clinical practice (Hyman and Loftus 1998), and for other situations in which memory reports are solicited. Many of these situations are highly stressful for the respondent. However, whether and how stress influences the incorporation of misinformation into established memories has not been tested yet. Therefore, we addressed this question in the present experiment using a standardized stressor and a modified version of the classical misinformation paradigm. Based on findings showing that stress impairs hippocampus-dependent encoding and updating processes, we predicted that stress would reduce the incorporation of misleading information into memory.

We tested this prediction in a sample of 64 healthy, nonsmoking university students without medication intake, drug abuse, or life-time history of any neurological or mental disorders (32 women, mean age, $24.3 \mathrm{yr}, \mathrm{SEM}=0.4 \mathrm{yr}$ ). Participants were tested on three consecutive days, $24 \mathrm{~h}$ apart: day 1, learning; day 2, stress manipulation and misinformation presentation;

(C) 2013 Schmidt et al. This article is distributed exclusively by Cold Spring Harbor Laboratory Press for the first 12 months after the full-issue publication date (see http://learnmem.cshlp.org/site/misc/terms.xhtml). After 12 months, it is available under a Creative Commons License (Attribution-NonCommercial 3.0 Unported), as described at http://creativecommons.org/licenses/by-nc/ $3.0 /$. 


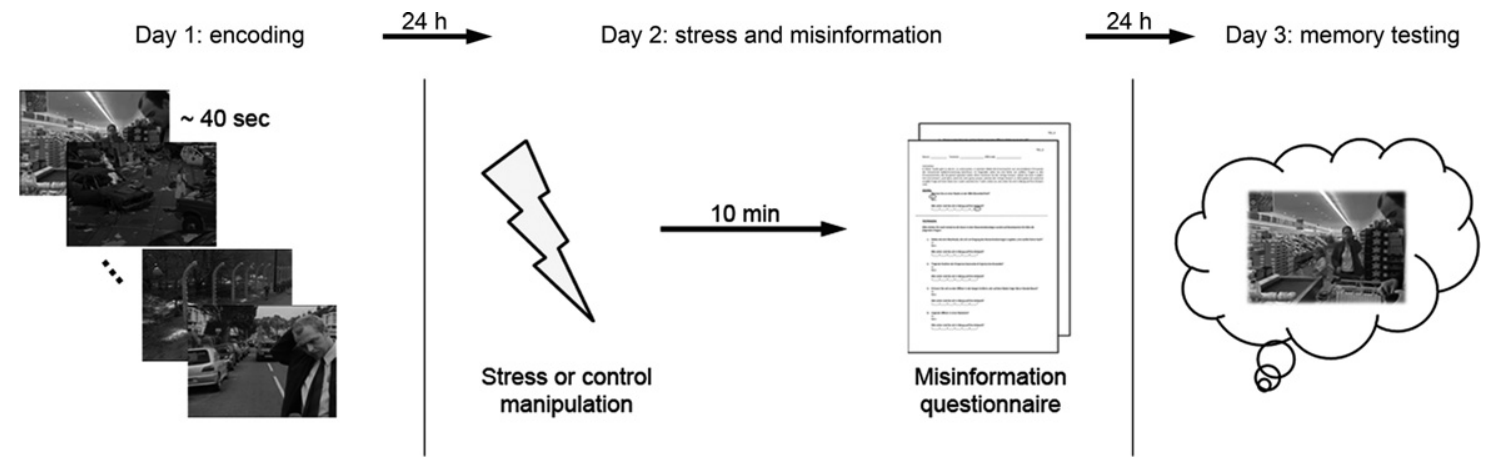

Figure 1. Illustration of the experimental procedure.

day 3, memory testing (Fig. 1). In order to control for the diurnal rhythm of the stress hormone cortisol, all testing took place in the afternoon.

On day 1, we first took physiological and subjective stress measurements to assess participants' stress level at encoding. Participants collected a saliva sample from which we subsequently analyzed cortisol concentrations using an immunoassay (IBL International). Furthermore, their blood pressure was measured with a Dinamap system (Critikon), and they completed a mood scale (MDBF) (Steyer et al. 1994) that measures three dimensions of subjective feeling (elevated vs. depressed mood, calmness vs. restlessness, and wakefulness vs. sleepiness). Afterward, participants were instructed to memorize eight movie clips, each about $40 \mathrm{sec}$ long, which were presented without sound on a computer screen. Because we also aimed to test whether the misinformation effect and its modulation by stress is influenced by the emotionality of the information, four of the clips were emotionally neutral (e.g., a cooking scene, a scene in the supermarket) and four were emotionally negative (e.g., a fight scene, a scene in a concentration camp).

On day 2, participants were randomly assigned to the stress or control condition (16 men and 16 women per group). In the stress condition, participants underwent the Trier Social Stress Test (TSST), a standardized laboratory stressor that is described in detail elsewhere (Kirschbaum et al. 1993). Briefly, participants were asked to give a 5-min free speech in which they had to promote their candidacy for a job tailored to their interests and to perform mental arithmetic for $5 \mathrm{~min}$ in front of an audience. The audience consisted of a man and a woman, both dressed in a white coat, sitting on a table opposite to the standing participant. Furthermore, participants were videotaped during their presentation. In the control condition, participants talked for $5 \mathrm{~min}$ about their last holidays and did some simple math on a sheet of paper. No audience was present and no video recordings were taken in the control condition. To assess the effectiveness of the stress induction, we took saliva samples, blood pressure measurements, and mood ratings immediately before as well as 1,10 , and 25 min after the treatment.

Ten minutes after the TSST/control manipulation, when peak cortisol levels were expected (Kirschbaum et al. 1993), participants filled out a questionnaire containing yes-no questions about the movie clips they had seen the day before. Importantly, some of the questions contained misleading information. For example, there was one clip showing prisoners dressed in gray and one question related to this clip was whether "the prisoners with the blackwhite striped clothing were wearing a hat."

On day 3, participants collected another saliva sample, their blood pressure was measured again, and they completed again the mood questionnaire. Next, participants completed a memory test consisting of six four-alternative forced-choice questions for each of the eight movie clips they saw on day 1 . Three questions were related to aspects that were correctly stated in the questionnaire on day 2 (control items), whereas the other three addressed aspects for which misinformation was presented on day 2 (misinformation items). For misinformation items, the four possible answers per question consisted of the correct answer (i.e., the original information), the misinformation, and two other incorrect answers (lures). Moreover, participants rated for all answers on a scale from 1 ("not at all") to 7 ("very") how certain they were that their answer was correct. Finally, participants rated the emotionality of the eight movie clips on a scale from -5 ("very negative") to 5 ("very positive"). In retrospect, these ratings confirmed that negative movie clips were, indeed, experienced as negative (mean rating, $-1.4, \mathrm{SEM}=0.3$ ) and neutral ones as relatively neutral (mean rating, 0.4 , SEM $=0.2$ ).

Before encoding on day 1, groups did not differ in their stress level (see Supplemental Table S1; all $t<1$, all $P>0.27$ ). Physiological and subjective changes on day 2 , however, confirmed the successful stress induction by the TSST (Table 1): salivary cortisol concentrations (treatment $\times$ time point of measurement interaction, $\left.F_{(3,186)}=19.72, P<0.001, \eta^{2}=0.26\right)$, systolic $\left(F_{(3,186)}=7.80, \quad P<0.001, \eta^{2}=0.11\right)$ and diastolic $\left(F_{(3,186)}=\right.$ $\left.8.22, P<0.001, \eta^{2}=0.12\right)$ blood pressure, increased and positive $\operatorname{mood}\left(F_{(3,186)}=11.71, \quad P<0.001, \quad \eta^{2}=0.16\right)$, and calmness $\left(F_{(3,186)}=8.35, P<0.001, \eta^{2}=0.12\right)$ decreased in response to the stressor, but not in response to the control condition. Memory performance shortly after the treatment (i.e., in the misinformation questionnaire) was better for negative movie clips (mean percentage correct, $72.6 \%, \mathrm{SEM}=1.2$ ) than for neutral clips $\left(63.8 \%, \mathrm{SEM}=1.2\right.$; main effect of emotionality, $F_{(1,62)}=28.86$, $\left.P<0.001, \eta^{2}=0.32\right)$ and comparable in the two experimental groups (main effect treatment and treatment $\times$ emotionality interaction, both $F<1$, both $P>0.45$ ).

Our memory data on day 3 showed a pronounced misinformation effect (Fig. 2): participants endorsed a significant proportion of the misinformation when asked about the original event and they endorsed misinformation significantly more often than lures $\left(F_{(1,62)}=75.19, P<0.001, \eta^{2}=0.56\right)$. This effect was stronger for neutral $\left(F_{(1,62)}=88.73, P<0.001, \eta^{2}=0.60\right)$ than for negative $\left(F_{(1,62)}=6.47, P<0.05, \eta^{2}=0.10\right.$; emotionality $\times$ item type interaction, $\left.F_{(1,62)}=29.42, P<0.001, \eta^{2}=0.33\right)$ items. Moreover, irrespective of the experimental group, memory was significantly worse for items for which misinformation was provided on day 2 than for control items $\left(F_{(1,62)}=132.48, P<\right.$ $\left.0.001, \eta^{2}=0.69\right)$ and this effect was again stronger for neutral $\left(F_{(1,62)}=89.10, P<0.001, \eta^{2}=0.60\right)$ than for negative items $\left(F_{(1,62)}=41.79, P<0.001, \eta^{2}=0.41\right.$; emotionality $\times$ item type interaction, $\left.F_{(1,62)}=10.84, P<0.01, \eta^{2}=0.15\right)$. 
Table 1. Salivary cortisol ( $\mathrm{nmol} / \mathrm{L})$, blood pressure, and subjective feeling before and after the experimental treatment (TSST vs. control manipulation)

\begin{tabular}{lcr}
\hline & Stress group & Control group \\
\hline Salivary cortisol (nmol/L) & & \\
Before treatment & $8.08 \pm 0.89$ & $9.02 \pm 1.16$ \\
1-min post-treatment & $\mathbf{1 4 . 6 0} \pm \mathbf{1 . 6 7}$ & $10.01 \pm 1.08$ \\
10-min post-treatment & $\mathbf{2 1 . 0 9} \pm \mathbf{2 . 3 2}$ & $9.31 \pm 0.81$ \\
25-min post-treatment & $\mathbf{1 8 . 4 9} \pm \mathbf{2 . 1 3}$ & $7.68 \pm 0.69$ \\
Systolic blood pressure $(\mathrm{mmHg})$ & & \\
Before treatment & $125.09 \pm 2.50$ & $128.55 \pm 3.08$ \\
1-min post-treatment & $\mathbf{1 3 4 . 2 5} \pm \mathbf{3 . 0 0} *$ & $126.78 \pm 3.37$ \\
10-min post-treatment & $121.45 \pm 2.73$ & $118.16 \pm 2.78$ \\
25-min post-treatment & $116.48 \pm 2.48$ & $115.81 \pm 2.51$ \\
Diastolic blood pressure $(\mathrm{mmHg})$ & & \\
Before treatment & $67.25 \pm 1.06$ & $67.58 \pm 1.72$ \\
1-min post-treatment & $\mathbf{7 3 . 8 9} \pm \mathbf{1 . 4 9}$ & $67.77 \pm 1.83$ \\
10-min post-treatment & $70.13 \pm 1.64$ & $65.73 \pm 1.89$ \\
25-min post-treatment & $65.80 \pm 1.36$ & $64.58 \pm 1.51$ \\
Elevated mood & & \\
Before treatment & $32.66 \pm 0.88$ & $32.66 \pm 0.95$ \\
1-min post-treatment & $\mathbf{2 7 . 8 8} \pm \mathbf{1 . 0 0}$ & $33.44 \pm 0.87$ \\
10-min post-treatment & $\mathbf{3 0 . 6 9} \pm \mathbf{0 . 8 3}$ & $33.88 \pm 0.78$ \\
25-min post-treatment & $31.81 \pm 0.83$ & $33.78 \pm 0.82$ \\
Wakefulness & & \\
Before treatment & $29.03 \pm 1.05$ & $28.66 \pm 0.84$ \\
1-min post-treatment & $28.13 \pm 1.11$ & $29.69 \pm 0.89$ \\
10-min post-treatment & $29.00 \pm 1.06$ & $29.22 \pm 0.83$ \\
25-min post-treatment & $28.63 \pm 1.06$ & $29.56 \pm 0.97$ \\
Calmness & & \\
Before treatment & $29.63 \pm 1.92$ & $29.91 \pm 1.12$ \\
1-min post-treatment & $\mathbf{2 4 . 6 9} \pm \mathbf{1 . 1 4}$ & $30.66 \pm 1.16$ \\
10-min post-treatment & $28.97 \pm 0.83^{*}$ & $31.94 \pm 0.88$ \\
25-min post-treatment & $30.72 \pm 0.86$ & $32.81 \pm 0.87$ \\
\hline & & \\
\hline
\end{tabular}

Data represent mean \pm SEM. $\left({ }^{*}\right) P<0.05$ between groups, (bold) $P<0.05$ relative to baseline.

Most importantly, the endorsement of misinformation was significantly influenced by stress. A treatment $\times$ emotionality $\times$ response (original vs. misinformation vs. lures) ANOVA revealed a significant treatment $\times$ response interaction $\left(F_{(2,124)}=3.96\right.$, $\left.P=0.02, \eta^{2}=0.06\right)$, indicating that participants who were stressed before misinformation presentation on day 2 endorsed significantly fewer misinformation items than participants in the control group $\left(F_{(1,62)}=6.80, P=0.01, \eta^{2}=0.10\right)$, whereas groups did not differ in endorsement rates for original information $(P=0.11)$ and lures $(P=0.22)$. Groups were also comparable in their memory for control items $(P=0.95)$.

Overall, participants were more certain that their answer was correct when they selected the misinformation than when they chose lures $\left(F_{(1,62)}=27.43, P<0.001, \eta^{2}=0.31\right)$. However, participants' certainty ratings were not significantly influenced by stress (all $F<3$, all $P>0.08$ ) (Supplemental Fig. S1). Notably, there were no group differences in cortisol, blood pressure, or subjective feeling before memory testing on day 3 (all $t<1.4$, all $P>$ 0.19) (Supplemental Table S2).

To summarize, our data show that participants who were stressed before the presentation of misleading information about previous events endorsed fewer of these misinformation items in a subsequent memory test for the original event, suggesting that stress attenuates the misinformation effect. The misinformation effect is thought to reflect the relative strength of the memory of the misinformation vs. the memory of the original event (Loftus and Hoffman 1989; Okado and Stark 2005). For instance, if misinformation is presented a considerable time after an event happened, allowing the original memory to fade, misinformation is more likely to be incorporated into memory (Loftus et al. 1978). Moreover, enhanced activity of the hippocampus during encod- ing of misinformation increased the misinformation effect, whereas greater hippocampal activity during encoding of the original event reduced the misinformation effect (Okado and Stark 2005). Stress is known to disrupt hippocampus-dependent encoding processes (Diamond et al. 2006; Schwabe and Wolf 2012). Therefore, we argue that stress before misinformation presentation impaired the encoding of the misleading information, thus increasing the relative strength of the memory of the original event and reducing the incorporation of misinformation.

The idea that the misinformation effect depends on the degree of encoding of the misinformation relative to the degree of encoding of the original event is also supported by our finding that the misinformation effect was more pronounced for neutral than for negative events. Emotionally arousing events are typically better remembered than neutral events, as was the case in the present experiment. The superior memory for emotional material is caused by emotional arousal-related noradrenaline and amygdala activation which strengthen memory formation (McGaugh 2000). We suggest that the enhanced encoding of emotional events made these less susceptible to distortions by misinformation, which were all rather neutral. It is, however, important to note that there was also a misinformation effect for negative events, albeit weaker than for neutral events, indicating that misinformation can even be implanted into memories that are well encoded.

Creation of false memories by post-event misinformation can have serious implications for police investigations and court trials, in which suggestive and misleading questions may bias witnesses' memories (Schacter and Loftus 2013). The fact that stress reduced the misinformation effect therefore seems to suggest that stress has favorable effects on eyewitness testimony. There is, however, evidence demonstrating that stress impairs memory retrieval in general (De Quervain et al. 1998; Kuhlmann et al. 2005) and the accuracy of eyewitness testimony in particular (Deffenbacher et al. 2004). Thus, although stress may hamper the incorporation of misleading information into subsequent memory, it may also transiently reduce the accessibility of the memory for the original event.

In the classical misinformation paradigm (Loftus et al. 1978), the intervals between encoding, misinformation presentation, and memory testing were relatively short. Here, we modified this protocol and used 24-h intervals between these stages of the

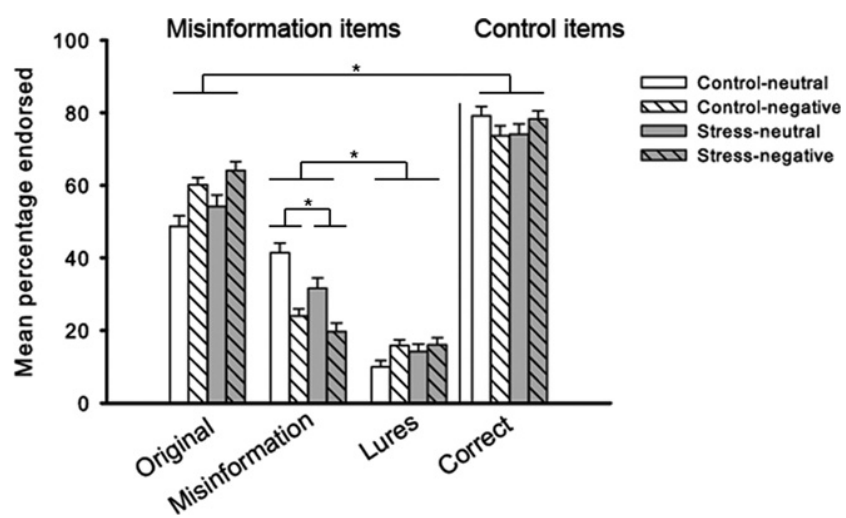

Figure 2. Mean endorsement rates for misinformation items (left) and hit rate for control items (right). Overall, hit rates were lower for misinformation items than for control items $\left(\left[{ }^{*}\right] P \leq 0.01\right)$ and participants endorsed misinformation more often than lures, thus demonstrating a misinformation effect. Critically, stressed participants endorsed fewer misinformation items than participants of the control group. Data represent means \pm SEM. 
misinformation paradigm in order to ensure that participants were stressed during misinformation presentation but not during encoding of the original memory or memory testing. Consequently, we were also able to assess the incorporation of misinformation into existing long-term memories and our findings demonstrate that misleading information can also be planted into consolidated memories, in line with the idea that seemingly stable memories may be susceptible to modifications again when they are reactivated (Hardt et al. 2010).

The misinformation effect is often referred to as an error or "sin" of memory (Schacter 1999). However, the incorporation of misleading post-event information points also to the dynamic nature of memory, allowing memories to be updated in the light of new information. The capability to integrate new information into existing memories is an essential feature of memory that is crucial in ever-changing environments. Hormones and neurotransmitters that are released during stress help us to form lasting memories of the stressful episode (Joëls et al. 2011), but at the same time suppress the retrieval of previous experiences (De Quervain et al. 1998; Kuhlmann et al. 2005), the flexible use of knowledge (Schwabe and Wolf 2013), or the updating of memories. Our findings suggest that a positive side effect of the stress-induced impairment of memory updating is that, shortly after stressor onset, we are less prone to incorporate misleading information into our memory.

\section{Acknowledgments}

We thank Patricia Nixon, Ann-Christin Boysen, and Martin Raad for help with data collection.

\section{References}

Deffenbacher KA, Bornstein BH, Penrod SD, McGorty EK. 2004. A meta-analytic review of the effects of high stress on eyewitness memory. Law Hum Behav 28: 687-706.

de Kloet ER, Joëls M, Holsboer F. 2005. Stress and the brain: From adaptation to disease. Nat Rev Neurosci 6: 463-475.

De Quervain DJ, Roozendaal B, McGaugh JL. 1998. Stress and glucocorticoids impair retrieval of long-term spatial memory. Nature 394: $787-790$.

Diamond DM, Park CR, Heman KL, Rose GM. 1999. Exposing rats to a predator impairs spatial working memory in the radial arm water maze. Hippocampus 9: 542-552.

Diamond DM, Campbell AM, Park CR, Woodson JC, Conrad CD, Bachstetter AD, Mervis RF. 2006. Influence of predator stress on the consolidation versus retrieval of long-term spatial memory and hippocampal spinogenesis. Hippocampus 16: 571-576.

Diamond DM, Campbell AM, Park CR, Halonen J, Zoladz PR. 2007. The temporal dynamics model of emotional memory processing: A synthesis on the neurobiological basis of stress-induced amnesia, flashbulb and traumatic memories, and the Yerkes-Dodson law. Neural Plast 2007: 60803.

Hardt O, Einarsson EÖ, Nader K. 2010. A bridge over troubled water: Reconsolidation as a link between cognitive and neuroscientific memory research traditions. Ann Rev Psychol 61: $141-167$.
Hupbach A, Gomez R, Hardt O, Nadel L. 2007. Reconsolidation of episodic memories: A subtle reminder triggers integration of new information. Learn Mem 14: 47-53.

Hyman IE, Loftus EF. 1998. Errors in autobiographical memory. Clin Psychol Rev 18: $933-947$.

Joëls M, Fernandez G, Roozendaal B. 2011. Stress and emotional memory: A matter of timing. Trends Cogn Sci 15: 280-286.

Karst H, Berger S, Turiault M, Tronche F, Schutz G, Joëls M. 2005. Mineralocorticoid receptors are indispensable for nongenomic modulation of hippocampal glutamate transmission by corticosterone. Proc Natl Acad Sci 102: 19204-19207.

Kim JJ, Diamond DM. 2002. The stressed hippocampus, synaptic plasticity and lost memories. Nat Rev Neurosci 3: 453-462.

Kirschbaum C, Pirke KM, Hellhammer DH. 1993. The 'Trier Social Stress Test' - a tool for investigating psychobiological stress responses in a laboratory setting. Neuropsychobiology 28: 76-81.

Kuhlmann S, Piel M, Wolf OT. 2005. Impaired memory retrieval after psychosocial stress in healthy young men. J Neurosci 25: 2977-2982.

Li Z, Richter-Levin G. 2013. Priming stimulation of basal but not lateral amygdala affects long-term potentiation in the rat dentate gyrus in vivo. Neuroscience 246: 13-21.

Loftus EF. 2005. Planting misinformation in the human mind: A 30-year investigation of the malleability of memory. Learn Mem 12: $361-366$.

Loftus EF, Hoffman HG. 1989. Misinformation and memory: The creation of false memories. J Exp Psychol: Gen 118: 100-104.

Loftus EF, Miller DG, Burns HJ. 1978. Semantic integration of verbal information into a visual memory. J Exp Psychol: Hum Learn Mem 4: $19-31$.

Maroun M, Akirav I. 2008. Arousal and stress effects on consolidation and reconsolidation of recognition memory. Neuropsychopharmacology 33: 394-405.

McGaugh J. 2000. Memory-a century of consolidation. Science 287: $248-251$.

Okado Y, Stark CEL. 2005. Neural activity during encoding predicts false memories created by misinformation. Learn Mem 12: 3-11.

Payne JD, Jackson ED, Hoscheidt S, Ryan L, Jacobs WJ, Nadel L. 2007. Stress administered prior to encoding impairs neutral but enhances emotional long-term episodic memories. Learn Mem 14: 861-868.

Schacter DL. 1999. The seven sins of memory: Insights from psychology and cognitive neuroscience. Am Psychol 54: 182-203.

Schacter DL, Loftus EF. 2013. Memory and law: What can cognitive neuroscience contribute? Nat Neurosci 16: 119-123.

Schacter DL, Guerin SA, St Jacques PL. 2011. Memory distortion: An adaptive perspective. Trends Cogn Sci 15: 467-474.

Schwabe L, Wolf OT. 2010. Stress impairs the reconsolidation of autobiographical memories. Neurobiol Learn Mem 94: 153-157.

Schwabe L, Wolf OT. 2012. Stress modulates the engagement of multiple memory systems in classification learning. J Neurosci 32: 11042-11049.

Schwabe L, Wolf OT. 2013. Stress and multiple memory systems: From 'thinking' to 'doing'. Trends Cogn Sci 17: 60-68.

Schwabe L, Bohringer A, Wolf OT. 2009. Stress disrupts context-dependent memory. Learn Mem 16: 110-113.

Schwabe L, Joëls M, Roozendaal B, Wolf OT, Oitzl MS. 2012a. Stress effects on memory: An update and integration. Neurosci Biobehav Rev 36: 1740-1749.

Schwabe L, Nader K, Wolf OT, Beaudry T, Pruessner JC. 2012b. Neural signature of reconsolidation impairments by propranolol in humans. Biol Psychiatry 71: 380-386.

Steyer R, Schwenkmezger P, Notz P, Eid M. 1994. Testtheoretische Analysen des Mehrdimensionalen Befindlichkeitsfragebogens (MDBF). Diagnostica 40: 320-328.

Received September 4, 2013; accepted in revised form October 14, 2013. 


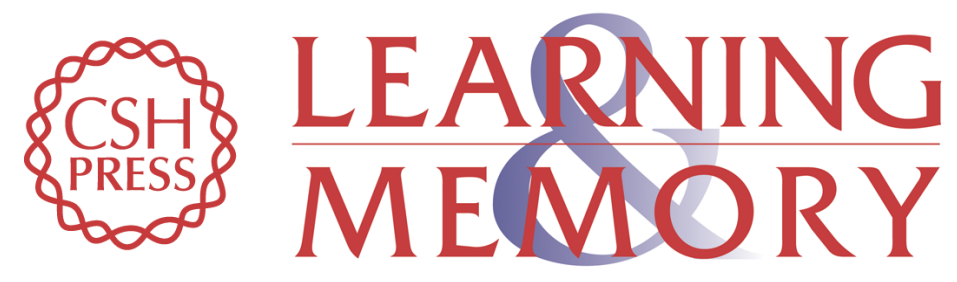

\section{Stress reduces the incorporation of misinformation into an established memory}

Pia-Isabell Schmidt, Kristin Rosga, Celina Schatto, et al.

Learn. Mem. 2014, 21:

Access the most recent version at doi:10.1101/Im.033043.113

\section{Supplemental http://learnmem.cshlp.org/content/suppl/2014/01/10/21.1.5.DC1 Material}

References This article cites 32 articles, 9 of which can be accessed free at: http://learnmem.cshlp.org/content/21/1/5.full.html\#ref-list-1

Creative This article is distributed exclusively by Cold Spring Harbor Laboratory Press for the Commons first 12 months after the full-issue publication date (see

License http://learnmem.cshlp.org/site/misc/terms.xhtml). After 12 months, it is available under a Creative Commons License (Attribution-NonCommercial 3.0 Unported), as described at http://creativecommons.org/licenses/by-nc/3.0/.

Email Alerting Receive free email alerts when new articles cite this article - sign up in the box at the Service top right corner of the article or click here. 